\title{
Outcomes after mitral valve repair: A single-center 16-year experience
}

\author{
James M. Tatum, MD, ${ }^{a}$ Michael E. Bowdish, MD, ${ }^{a}$ Wendy J. Mack, PhD, ${ }^{b}$ Adrienne M. Quinn, MPH, ${ }^{a}$ \\ Robbin G. Cohen, MD, ${ }^{a}$ Amy E. Hackmann, MD, ${ }^{a}$ Mark L. Barr, MD, ${ }^{a}$ and Vaughn A. Starnes, MD $^{a}$
}

\section{ABSTRACT}

Objective: To evaluate outcomes after mitral valve repair.

Methods: Between May 1999 and June 2015, 446 patients underwent mitral valve repair. Isolated mitral valve annuloplasty was excluded. A total of $398(89 \%)$ had degenerative valve disease. Mean follow-up was $5.5 \pm 3.8$ years. Postoperative echocardiograms were obtained in 334 patients $(75 \%)$ at a mean of $24.3 \pm 13.7$ months.

Results: Survival was $97 \%, 96 \%, 95 \%$, and $94 \%$ at $1,3,5$, and 10 years. Risk factor analysis showed age $>60$ years and nondegenerative etiology predict death (hazard ratio, 2.91; 95\% confidence interval, 1.06-8.02, $P=.038$; and hazard ratio, $1.87 ; 95 \%$ confidence interval, $1.16-3.02, P=.010$, respectively). Considering competing risks due to mortality, the cumulative incidence of reoperation was $2.8 \%, 4.2 \%, 5.1 \%$, and $9.6 \%$ at $1,3,5$, and 10 years. Competing risk proportional hazard survival regression identified nondegenerative etiology and previous cardiac surgery as predictors of reoperation, and posterior repair was protective (all $P<.05$ ). Cumulative incidence of progression of mitral regurgitation ( 2 or more grades) with mortality as a competing risk was $4.7 \%, 10.5 \%$, $21.0 \%$, and $35.8 \%$ at $1,3,5$, and 10 years. Patients with previous sternotomy, repair or coronary artery bypass grafting, and concurrent tricuspid valve procedure or isolated anterior leaflet repair were more likely to develop progression of mitral regurgitation (all $P<.05$ ), and posterior leaflet repair was protective $(P=.038)$. On multivariate analysis diabetes, previous coronary artery bypass grafting and concurrent tricuspid valve intervention predicted MR progression.

Conclusions: Mitral valve repair has excellent outcomes. Our results demonstrate failures appear to occur less in those who undergo posterior leaflet repair. ( $\mathbf{J}$ Thorac Cardiovasc Surg 2017;154:822-30)

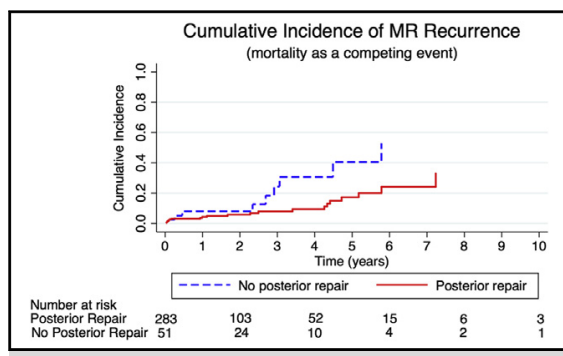

Cumulative incidence of progression of mitral regurgitation by posterior leaflet repair.

\section{Central Message}

Mitral valve repair is associated with excellent survival, reoperation rates, and durability, especially in those undergoing posterior leaflet repairs.

\section{Perspective}

Recurrence of mitral regurgitation after mitral valve repair is associated with increased morbidity and mortality. Current outcomes with mitral valve repair are excellent particularly in those who require posterior leaflet repairs. We should consider these surgical results in an era of potential increased application of percutaneous mitral valve therapy.

See Editorial Commentary page 831.
Mitral valve repair is accepted widely to improve survival and quality of life. ${ }^{1,2}$ Rates of reoperation and the progression of mitral regurgitation (MR) after mitral valve repair vary widely. In addition, numerous studies demonstrate a persistent failure rate after repair inherently

\footnotetext{
From the Departments of a Surgery and ${ }^{\mathrm{b}}$ Preventive Medicine, Keck School of Medicine of USC, University of Southern California, Los Angeles, Calif.

Research reported in this publication was supported by the Department of Surgery of the Keck School of Medicine of USC, and the National Center for Advancing Translational Sciences of the National Institutes of Health under Award Number UL1TR000130 (formerly by the National Center for Research Resources, Award Number UL1RR031986). Dr Bowdish is the principal investigator of the USC Cardiothoracic Surgical Trials Network Core Site as part of the Cardiothoracic Surgical Trials Network. He is funded partially by grant 1-UM-HL11794 from the National Heart, Lung, and Blood Institute of the National Institutes of Health. The content is solely the responsibility of the authors and does not necessarily represent the official views of the Cardiothoracic Surgical Trials Network, the National Heart, Lung, and Blood Institute, or the National Institutes of Health.
}

related to the inability of surgery to correct the underlying disease process. ${ }^{3-16}$ The Brigham and Women's Hospital group reported a 20-year incidence of mitral reoperation of $18 \%$, whereas the Toronto group reported a reoperation rate of only $5.9 \% .{ }^{6}$ Recurrence of moderate-to-severe MR

Drs Tatum and Bowdish contributed equally to this work.

Read at the 96th Annual Meeting of The American Association for Thoracic Surgery, Baltimore, Maryland, May 14-18, 2016.

Received for publication May 16, 2016; revisions received Dec 18, 2016; accepted for publication Jan 8, 2017; available ahead of print March 7, 2017.

Address for reprints: Michael E. Bowdish, MD, Department of Surgery, Keck School of Medicine of USC, University of Southern California, 1520 San Pablo St, Suite 4300, Los Angeles, CA 90033 (E-mail: Michael.Bowdish@med.usc.edu). $0022-5223 / \$ 36.00$

Copyright (C) 2017 by The American Association for Thoracic Surgery http://dx.doi.org/10.1016/j.jtcvs.2017.01.047 

Abbreviations and Acronyms
$\mathrm{CI}=$ confidence interval
$\mathrm{HR}=$ hazard ratio
$\mathrm{MR}=$ mitral regurgitation
$\mathrm{SHR}=$ subhazard ratio
TTE $=$ transthoracic echocardiography
$\mathrm{USC}=$ University of Southern California

\section{Scanning this QR code will take you to a procedural video, supple- mental figure, and tables for this article.}

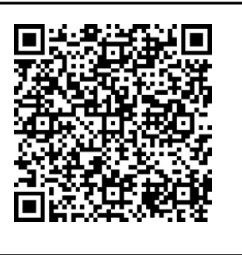

at 20 years in the latter study was $30.8 \%$, whereas the Mayo clinic group recently reported a 15 -year incidence of significant recurrent MR of $13.3 \% .^{6-8}$ Risk factors for the recurrence of MR after mitral valve repair vary greatly but most consistently include factors such as presence of anterior or bileaflet pathology, absence of posterior leaflet pathology, lack of an annuloplasty ring, and longer cardiopulmonary bypass times..$^{6-9}$

We sought to examine outcomes of mitral valve repair and analyze risk factors for death, reoperation, and progression of MR. An analysis of this nature is especially timely, given the increasing adoption of percutaneous mitral valve repair and replacement technology.

\section{MATERIALS AND METHODS}

This study was conducted in accordance to the "Guidelines for reporting mortality and morbidity after cardiac valve interventions." ${ }^{17}$ This was a systematic retrospective cohort study of consecutive patients undergoing mitral valve repair at the University of Southern California (USC; formerly USC University Hospital, now Keck Hospital of USC) between May 1999 and July 2015. The follow-up period closed July 2016. Mitral valve repair was defined as mitral valve reconstruction with or without an annuloplasty ring. Patients who underwent isolated mitral valve annuloplasty for the treatment of MR were excluded. Patients undergoing other concomitant cardiac procedures were included. The institutional review board of the University of Southern California Health Sciences Campus approved this study (HS-15-00509) and waived the requirement for patient consent. The senior author performed $85 \%$ of the procedures.

Patients, baseline demographics, operative characteristics, and perioperative outcomes were identified through the USC Cardiac Surgery Research Database and our Society of Thoracic Surgeons Adult Cardiac Database. Subsequent outcomes (follow-up transthoracic echocardiograms [TTEs], need for reoperation, and mortality) were collected actively and passively. All available medical records from our electronic medical record and the referring providers were reviewed. Recurrent MR was assessed from the report of an institutional or outside facility echocardiogram. Reoperation is defined as a repeat operation to the mitral valve, ie, second mitral valve repair or mitral valve replacement. No patient received a mitral valve clip or valve in band. Mortality was confirmed through direct patient, family, or provider contact; a search of local obituaries; and through access

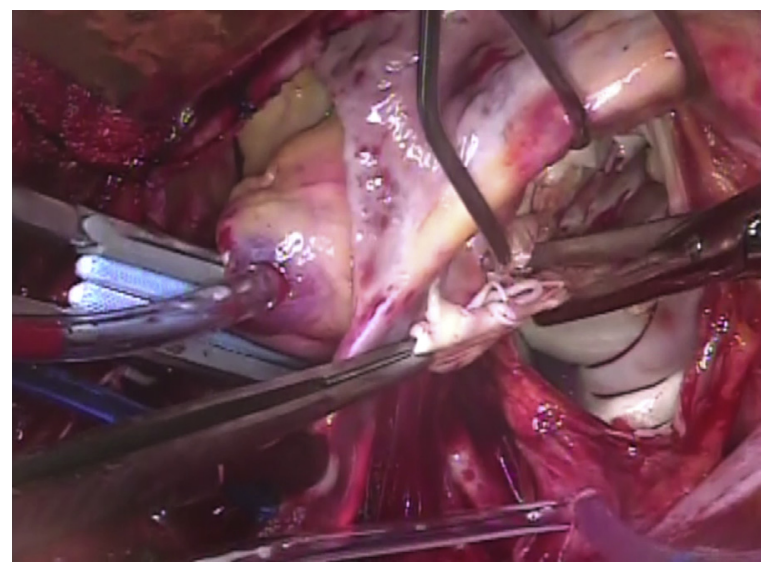

VIDEO 1. Minimally invasive mitral valve repair of myxomatous disease. $\mathrm{P} 2$ is resected, folding valvuloplasty of $\mathrm{P} 1$ and $\mathrm{P} 3$ is performed, followed by reconstruction of the posterior leaflet. A neochord is placed to A1, which is secured after placement of a partial annuloplasty ring and distension of left ventricle to ensure proper neochordal height. Video available at: http:// www.jtcvsonline.org/article/S0022-5223(17)30185-X/addons.

of the Social Security Death Index in collaboration with the University of California at San Francisco Clinical Translational Science Institute. Follow-up TTEs were not obtained at fixed time points but at the discretion of the physician.

The primary endpoints were mortality, need for mitral valve reoperation, and the progression of MR. MR was coded 0 to 4 based on echocardiogram reports $(0=$ none, $1=$ trace, $2=$ mild, $2.5=$ mild-to-moderate, $3=$ moderate, $3.5=$ moderate-to-severe, $4=$ severe). Progression of MR was defined as worsening of MR by more than 2 grades. As a secondary assessment, the incidence of grade 3.5 or 4 (moderate-to-severe or severe) MR over time was included.

Patients with partial follow-up were included; however, only patients with mortality data were included in the analysis of mitral reoperation or recurrence. Patients were censored from further recurrence analysis on the event of reoperation.

Surgical approach was either full sternotomy or minimally invasive right thoracotomy as per surgeon's preference. The mitral valve typically was accessed via the interatrial sulcus, although transseptal and left atrial dome approaches also were used. Peripheral cannulation was used for the minimally invasive approach. Posterior leaflet mitral valve repair generally involved resection of the diseased segment, annular plication, and reconstruction of the posterior leaflet (Video 1). The anterior leaflet was repaired by the placement of polytetrafluoroethylene neochordae (W. L. Gore \& Associates, Inc, Flagstaff, Ariz) or resection and reconstruction. A true-sized, partial posterior mitral valve annuloplasty primarily was used.

\section{Statistical Analysis}

Preoperative and operative characteristics were summarized. For mortality, Cox proportional hazards regression was used to estimate and test associations of variables with time-to-event; Kaplan-Meier survival curves were used and comparisons between groups were made by log-rank tests. Statistical analysis of time to reoperation and MR recurrence considered mortality as a competing risk event. Nonparametric estimates of cumulative incidence (probability of reoperation or MR recurrence) were calculated. ${ }^{18}$ Survival regression used competing risks analysis with the Fine-Gray model ${ }^{19}$; results are presented as subhazard ratios (SHRs) and $95 \%$ confidence intervals (CIs). Characteristics that were associated with time-to-event at $P<.10$ on univariate analysis were selected for 
TABLE 1. Preoperative and operative characteristics of entire cohort

Entire cohort,

$\mathrm{N}=446$

Preoperative characteristics

Age, y

Male

Nonwhite race

Body mass index, $\mathrm{kg} / \mathrm{m}^{2}$

NYHA class*

Diabetes

Atrial fibrillation

COPD

Previous myocardial infarction

Previous CVA

Renal failure

Ejection fraction, \%

Previous cardiac surgery

Sternotomy

Previous mitral valve surgery

CABG

Any valve

Preoperative mitral valve assessment (echocardiogram)

Leaflet involvement

Anterior

Posterior

Anterior and posterior

Indeterminate

Preoperative MR grade

$0-2.5$

3-3.5

4

Etiology

Degenerative

Other

Operative characteristics

Cardiopulmonary bypass time, $\min$

Cardiopulmonary bypass time $>90 \mathrm{~min}$

Crossclamp time, min

Isolated mitral valve repair

Minimally invasive mitral valve repair

Concurrent procedure

CABG

Aortic valve

Tricuspid valve

Aortic procedure

Ablation procedure

Septal myectomy

IABP

Ventricular assist device placement

Peripheral arterial cannulation

Need for second cardiopulmonary bypass

Minimally invasive incision

Type of mitral annuloplasty

None

Partial

Complete
$61 \pm 13$

$296(66)$

$103(23)$

$26 \pm 5$

$2(2,3)$

$37(8.3)$

$48(10.8)$

$37(8.3)$

23 (5.2)

15 (3.4)

14 (3.1)

$60 \pm 10$

$23(5.2)$

$9(2.0)$

$8(1.8)$

15 (3.4)

58 (13.0)

320 (71.7)

52 (11.7)

16 (3.6)

$25(5.7)$

$62(14.2)$

351 (80.1)

$398(89.2)$

$48(10.8)$

$93 \pm 43$

172 (39.5)

$65 \pm 35$

306 (68.6)

$237(53.1)$

$21(4.7)$

$24(5.4)$

$31(7.0)$

$13(2.9)$

53 (11.9)

7 (1.6)

8 (1.8)

$1(0.2)$

278 (62.3)

$11(2.5)$

$281(63.0)$

$12(2.7)$

434 (97.3)

0

(Continued)
TABLE 1. Continued

Entire cohort,

$\mathrm{N}=\mathbf{4 4 6}$

Size of mitral annuloplasty, mm

26-29

$104(24.0)$

30-31

$117(27.0)$

32-34

$169(39.0)$

36-38

$43(9.9)$

Type of mitral valve repair

Any posterior leaflet repair

$377(84.5)$

Isolated posterior leaflet repair

$314(70.4)$

Any anterior leaflet repair

$132(29.5)$

Isolated anterior leaflet repair

$69(15.5)$

Bileaflet repair

$63(14.1)$

Continuous variables are expressed as mean \pm standard deviation; categorical variables are expressed as frequency (percent). NYHA, New York Heart Association; $C O P D$, chronic obstructive pulmonary disease; $C V A$, cerebral vascular accident; $C A B G$, coronary artery bypass graft; $M R$, mitral regurgitation; $I A B P$, intra-aortic balloon pump. *NYHA expressed as median (25th, 75th percentiles); group differences tested with Wilcoxon rank sum.

multivariate modeling. Final multivariate models for each outcome included characteristics that were significant at $P<.05$. Results are presented as hazard ratio (HR) and 95\% CI. Data were collected with a Microsoft Excel spreadsheet (Microsoft Corp, Redmond, Wash) and further analyzed with STATA Version 14 (Statistical Software, College Station, Tex).

\section{RESULTS}

\section{Characteristics of Overall Cohort}

A total of 1754 mitral valve procedures were performed during this time period, of which $810(46 \%)$ were mitral valve repairs and 944 (54\%) were mitral valve replacements. Of the repairs, 446 involved mitral valve repair with or without mitral valve annuloplasty and met inclusion criteria $(25 \%$ of all mitral valve procedures and $55 \%$ of all mitral valve repairs, see Table E1). A Consolidated Standards of Reporting Trials type diagram is included in Figure E1. Preoperative and operative characteristics are shown in Table 1. The cohort was relatively young (61 \pm 13 years) with few comorbidities and moderate-tosevere or severe MR with mild-to-moderate symptoms. Most $(89 \%)$ had degenerative disease, and $34 \%$ were female.

The posterior leaflet was most repaired commonly $(84 \%)$ and, of these, $83 \%$ were isolated posterior leaflet repairs. One third had an anterior leaflet repair and, of these, one half were isolated anterior leaflet repairs.

More than one half of patients underwent a minimally invasive approach $(63 \%)$. Of the $69 \%$ who underwent isolated mitral valve repair, $77 \%$ had a minimally invasive approach. Minimally invasive thoracotomy was converted to full sternotomy in one case $(<1 \%)$. For the sternotomy group, average cardiopulmonary and crossclamp times were 112 and 81 minutes, respectively, whereas these times 


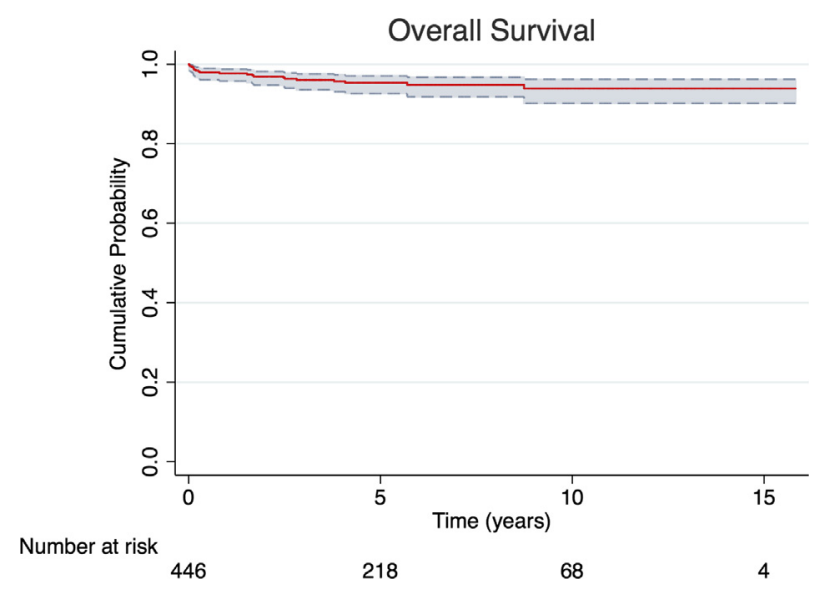

FIGURE 1. Kaplan-Meier survival for entire cohort.

were 82 and 55 minutes, respectively, in the minimally invasive group. This difference reflects the greater number of concomitant procedures via sternotomy (data not shown).

Intraoperative transesophageal echocardiography results were available in $93.3 \%$ of patients. Ninety-nine percent of patients left the operating room with less than grade $2 \mathrm{MR}$, and none left the operating room with more than grade 2.5 MR. Intraoperative transesophageal echocardiography revealed persistent MR secondary to systolic anterior motion in $9(2 \%)$ patients, all of which were successfully repaired on second attempt.

There were concurrent cardiac surgery procedures in 145 $(33 \%)$ patients, most commonly an ablation procedure for atrial fibrillation (33.5\% of concurrent procedures). Of the 31 patients who had concomitant tricuspid valve surgery, all had moderate-to-severe or severe tricuspid regurgitation preoperatively. Of these, 27 underwent tricuspid valve annuloplasty while the remainder had primary repair, a DeVega procedure, or replacement. Average tricuspid annuloplasty ring size was $34 \pm 2.1 \mathrm{~mm}$.

\section{Survival}

Follow-up data for mortality were available in all patients at a mean of $5.5 \pm 3.8$ years (range $0-15.8$ years). Mortality occurred in 20 patients during the study period. Thirty-day mortality was $0.9 \%$. Kaplan-Meier survival was $97 \%$, $96 \%, 95 \%$, and $94 \%$ at $1,3,5$, and 10 years (Figure 1, CIs reported in Table E2). Risk factor analysis for mortality is shown in Table 2. Age $>60$ years and nondegenerative etiology were predictive of death (HR, $2.91 ; 95 \% \mathrm{CI}$, 1.06-8.02, $P=.038$; and HR, 1.87 ; $95 \%$ CI, 1.16-3.02, $P=.010$, respectively).

\section{Need for Mitral Valve Reoperation}

Follow-up data for mitral valve reoperation were available in 364 patients $(82 \%)$ at a mean of $5.3 \pm 3.7$ years (range 0-15.4 years). Characteristics of those with and without reoperative data available for analysis are shown in Table E3. Reoperation was required in 24 patients. Considering competing risks due to mortality, the cumulative incidence of mitral valve reoperation was $2.8 \%$, $4.2 \%, 5.1 \%$, and $9.6 \%$ at $1,3,5$, and 10 years. Competing risk proportional hazard survival regression incorporating mortality as a competing risk identified nondegenerative etiology and previous cardiac surgery as predictors of reoperation, whereas any posterior repair was protective

TABLE 2. Risk factor analysis of mortality and reoperation

\begin{tabular}{|c|c|c|c|c|c|c|c|c|c|}
\hline \multirow[b]{3}{*}{ Variable } & \multirow{3}{*}{$\begin{array}{c}\text { Overall } \\
(\mathrm{N}=\mathbf{4 4 6}) \\
\end{array}$} & \multicolumn{4}{|c|}{ Mortality $(n=20)$} & \multicolumn{4}{|c|}{ Reoperation $(n=24)$} \\
\hline & & \multirow[b]{2}{*}{ Yes } & \multirow[b]{2}{*}{ No } & \multicolumn{2}{|c|}{$\begin{array}{c}\text { Cox proportional } \\
\text { hazard regression* }\end{array}$} & \multirow[b]{2}{*}{ Yes } & \multirow[b]{2}{*}{ No } & \multicolumn{2}{|c|}{$\begin{array}{c}\text { Competing risk } \\
\text { proportional hazard regression }\end{array}$} \\
\hline & & & & HR $(95 \%$ CI) & $P$ value $\dagger$ & & & SHR $(95 \%$ CI $)$ & $P$ value* \\
\hline Sex (male) & 296 & 11 & 285 & $0.56(0.23-1.36)$ & .201 & 17 & 222 & $1.23(0.52-2.90)$ & \\
\hline Age, $y$ & $61 \pm 13$ & $67 \pm 14$ & $60 \pm 13$ & & & $60 \pm 14$ & $61 \pm 13$ & & \\
\hline Age $>60 y, n$ & 231 & 15 & 216 & $2.91(1.06-8.02)$ & .038 & 12 & 174 & $1.00(0.45-2.20)$ & 1.00 \\
\hline Nondegenerative etiology, $\mathrm{n}$ & 48 & 6 & 42 & $1.87(1.16-3.02)$ & .010 & 9 & 39 & $2.39(1.57-3.64)$ & $<.001$ \\
\hline Previous cardiac surgery, $n$ & 23 & 2 & 21 & $1.84(0.43-7.94)$ & .414 & 4 & 12 & $4.18(1.55-11.3)$ & .005 \\
\hline Concurrent surgery, $\mathrm{n}$ & 145 & 9 & 136 & $1.67(0.69-4.03)$ & .255 & 11 & 108 & $1.76(0.81-3.83)$ & .16 \\
\hline Concurrent TV surgery, $\mathrm{n}$ & 31 & 3 & 28 & $2.61(0.76-8.93)$ & .127 & 2 & 25 & $1.54(0.40-5.94)$ & .53 \\
\hline Any anterior repair, $\mathrm{n}$ & 132 & 8 & 124 & $1.57(0.64-3.84)$ & .323 & 11 & 97 & $1.89(0.86-4.16)$ & .12 \\
\hline Any posterior repair, $\mathrm{n}$ & 377 & 16 & 361 & $0.76(0.25-2.28)$ & .626 & 15 & 291 & $0.34(0.15-0.75)$ & .007 \\
\hline Cardiopulmonary bypass, min & $93 \pm 43$ & $110 \pm 57$ & $92 \pm 42$ & & & $98 \pm 40$ & $93 \pm 43$ & & \\
\hline$>90 \min , \mathrm{n}$ & 183 & 10 & 173 & $1.44(0.60-3.46)$ & .416 & 10 & 125 & $1.22(0.54-2.74)$ & .63 \\
\hline Crossclamp time & $65 \pm 35$ & $76 \pm 38$ & $64 \pm 34$ & & & $62 \pm 32$ & $65 \pm 35$ & & \\
\hline$>60 \min , \mathrm{n}$ & 183 & 12 & 171 & $2.30(0.94-5.64)$ & .068 & 7 & 129 & $0.75(0.31-1.81)$ & .53 \\
\hline
\end{tabular}




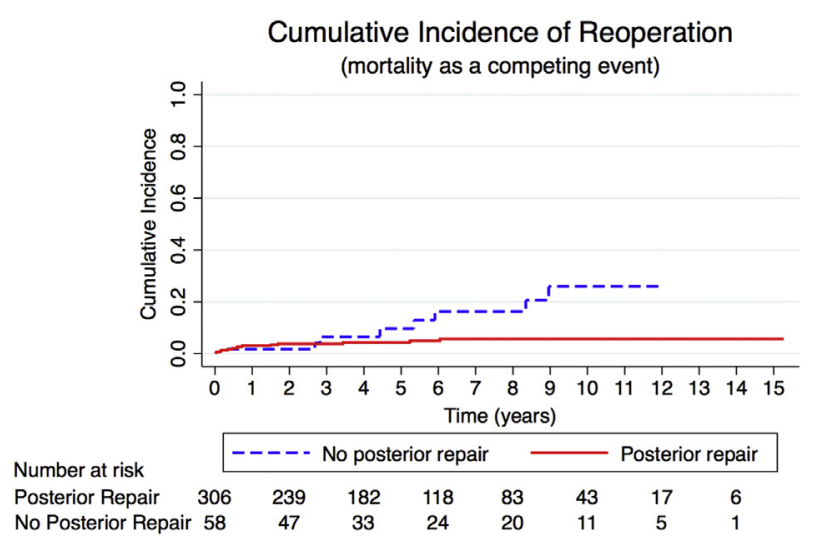

FIGURE 2. Nonparametric estimates of cumulative incidence of the probability of reoperation with death as a competing outcome for presence (dashed line) or absence (solid line) of any posterior leaflet repair. Table E2 for confidence intervals.

(all $P<.05$ ). Concomitant surgery was of borderline increased risk $(P=.076)$ (Table 2). Nonparametric estimates of cumulative incidence of the probability of reoperation based on the presence or absence of a posterior leaflet repair (with mortality as a competing outcome) are shown in Figure 2 (CIs reported in Table E2).

\section{Progression of MR}

Follow-up data for progression of MR were available in 334 patients $(75 \%)$ at a mean of $2.0 \pm 1.1$ years (range 0-15.2 years). Characteristics of those with and without progression of MR data available for analysis is shown in Table E4. In the 17 patients with follow-up who left the operating room with either grade 2 or $2.5 \mathrm{MR}$, no patient developed progression to grade $4 \mathrm{MR}$.

MR progression of 2 or more grades occurred in 31 patients. When we considered competing risks due to mortality, the cumulative incidence of MR progression of 2 or more grades was $4.7 \%, 10.5 \%, 21.0 \%$, and $35.8 \%$ at 1 , 3,5 , and 10 years. Competing risk proportional hazard regression for recurrence of MR with mortality as a competing event is shown in Table 3. Patients with a previous sternotomy, previous mitral valve or coronary artery bypass grafting surgery, concurrent tricuspid valve procedure, or isolated anterior leaflet repair were more likely to develop progression of MR (all $P<.05$ ). Lower ejection fraction and advanced age were of borderline increased risk $(P=.06$ and .09 , respectively). Any posterior leaflet repair was protective from progression of MR $(P=.038)$. Nonparametric estimates of cumulative incidence of the recurrence of MR greater than 2 grades based on the presence or absence of a posterior leaflet repair (with death as a competing outcome) are shown in Figure 3 (CIs reported in Table E2).

When we used the secondary assessment of those with moderate-to-severe or severe MR (grade 3.5 or 4), the Kaplan-Meier freedom from recurrence improved to
$99 \%, 96 \%, 93 \%$, and $74 \%$ at $1,3,5$, and 10 years (this analysis did not account for death as a competing outcome).

The strong trend of posterior leaflet repair as a protector from MR progression over time also was demonstrated on multivariate analysis with mortality as a competing risk (SHR, 0.50; CI, 0.21-1.15, $P=.10$, Figure 4). In addition, diabetes, previous coronary artery bypass grafting, and concurrent tricuspid valve intervention remained predictors of progression of MR.

To analyze this further, we examined the 257 patients who underwent isolated resection of the posterior leaflet, segment 2. Follow-up TTE was available in 191 of these patients $(74 \%)$. Kaplan-Meier freedom from progression of MR by more than 2 grades was $97 \%, 92 \%$, and $77 \%$ at 1,3 , and 5 years. Although the HR was less than 1, this difference did not reach statistical significance $(0.46 ; 95 \% \mathrm{CI}$, $0.21-0.74, P=.12$ ).

\section{DISCUSSION}

This study analyzed outcomes after mitral valve repair. The key findings are that survival after mitral valve repair is excellent and need for reoperation is uncommon. In addition, there is a small but inherent failure risk over time, which appears less prominent with posterior leaflet repair.

Overall survival was excellent. Perioperative mortality was less than $1 \%$, and 10 -year survival was $94 \%$. These results are comparable with other series of mitral valve repair for predominantly degenerative disease. The Mount Sinai group reported a $0.8 \%$ in-hospital mortality and 1 - and 5 -year survival of 99 and $97 \%$, whereas the Brigham and Women's Hospital group reported a 30-day mortality of $0.6 \%$ and 10 -year survival of $79 \%{ }^{7,9}$ Risk factors for death included a nondegenerative etiology and age $>60$ years. Others have identified increasing age, New York Heart Association functional class, smoking history, coronary artery disease, chronic obstructive pulmonary disease, left ventricular ejection fraction, lack of annuloplasty ring, and recurrent MR as risk factors for mortality. 6,8

Need for mitral valve reoperation was uncommon in our cohort, with a cumulative incidence of $9.6 \%$ at 10 years, when we took death into consideration as a competing risk. Reoperation was slightly more common in our cohort than in other large series. Freedom from reoperation of $97 \%$ at 7 years, $90 \%$ to $96 \%$ at 10 years, and $93 \%$ at 15 years have been reported recently by various centers, although whether or not death was considered as a competing risk in these series is unclear. ${ }^{6-9}$ The absence of a posterior repair was correlated strongly with need for mitral reoperation in our series, although part of this effect is likely due to the $10 \%$ of patients with etiologies of nondegenerative nature.

Differences and challenges in follow-up make direct comparisons of recurrence rates difficult. The Mayo Clinic 
TABLE 3. Competing risk proportional hazard regression for recurrence of MR (mortality competing event)

\begin{tabular}{|c|c|c|}
\hline \multirow[b]{2}{*}{ Variable } & \multicolumn{2}{|c|}{$\begin{array}{l}\text { MR recurrence } \\
\text { (>2 grades) }\end{array}$} \\
\hline & SHR $(95 \%$ CI $)$ & $\begin{array}{c}P \\
\text { value }\end{array}$ \\
\hline \multicolumn{3}{|l|}{ Preoperative characteristics } \\
\hline Age (per $10 \mathrm{y}$ ) & $1.24(0.97-1.58)$ & .09 \\
\hline Male & $0.68(0.33-1.36)$ & .27 \\
\hline Nonwhite race & $0.94(0.36-2.43)$ & .90 \\
\hline Body mass index, $\mathrm{kg} / \mathrm{m}^{2}$ & $1.02(0.98-1.07)$ & .29 \\
\hline NYHA class & $1.08(0.63-1.86)$ & .77 \\
\hline Diabetes & $2.43(0.89-6.65)$ & .08 \\
\hline Atrial fibrillation & $1.24(0.43-3.51)$ & .69 \\
\hline COPD & $1.65(0.63-4.31)$ & .31 \\
\hline Previous myocardial Infarction & $1.06(0.13-8.50)$ & .96 \\
\hline Previous CVA & $1.15(0.18-7.30)$ & .88 \\
\hline Renal failure & $-*$ & \\
\hline Ejection fraction, $\%$ & $0.97(0.95-1.00)$ & .06 \\
\hline \multicolumn{3}{|l|}{ Previous cardiac surgery } \\
\hline Sternotomy & $3.97(1.51-10.45)$ & .005 \\
\hline Mitral valve & $4.33(1.60-11.72)$ & .004 \\
\hline CABG & $16.89(3.97-71.82)$ & $<.001$ \\
\hline Any valve & $1.63(0.44-5.98)$ & .47 \\
\hline \multicolumn{3}{|l|}{ Preoperative mitral valve assessment } \\
\hline \multicolumn{3}{|l|}{ Leaflet involvement } \\
\hline Anterior & 1.00 & \\
\hline Posterior & $0.72(0.30-1.75)$ & .47 \\
\hline Anterior and posterior & $0.51(0.12-2.13)$ & .35 \\
\hline Annulus & $-*$ & \\
\hline \multicolumn{3}{|l|}{ Preoperative MR grade } \\
\hline $1-2.5$ & 1.00 & \\
\hline 3-3.5 & $0.64(0.12-3.49)$ & .61 \\
\hline 4 & $0.81(0.19-3.45)$ & .78 \\
\hline \multicolumn{3}{|l|}{ Operative characteristics } \\
\hline Cardiopulmonary bypass time, $\min$ & $1.00(0.99-1.01)$ & .98 \\
\hline Cardiopulmonary bypass time $>90 \mathrm{~min}$ & $1.02(0.51-2.06)$ & .95 \\
\hline Crossclamp time & $1.00(0.99-1.01)$ & .55 \\
\hline Isolated mitral valve repair & $0.69(0.34-1.43)$ & .32 \\
\hline Minimally invasive & $0.75(0.36-1.55)$ & .43 \\
\hline \multicolumn{3}{|l|}{ Concurrent procedure } \\
\hline CABG & $1.03(0.21-5.11)$ & .97 \\
\hline Aortic valve & $0.90(0.22-3.62)$ & .88 \\
\hline Tricuspid valve & $4.10(1.59-10.58)$ & .004 \\
\hline Aortic procedure & $-*$ & \\
\hline Ablation procedure & $1.78(0.80-3.97)$ & .16 \\
\hline Septal myectomy & $2.73(0.33-22.29)$ & .35 \\
\hline IABP & $4.49(0.53-38.06)$ & .17 \\
\hline Ventricular assist device placement & $-*$ & \\
\hline Peripheral arterial cannulation & $1.41(0.68-2.92)$ & .36 \\
\hline $\begin{array}{l}\text { Need for second cardiopulmonary } \\
\text { bypass }\end{array}$ & $-*$ & \\
\hline Minimally invasive incision & $1.31(0.61-2.78)$ & .49 \\
\hline \multicolumn{3}{|l|}{ Type of mitral annuloplasty } \\
\hline None & 1.00 & \\
\hline Partial & $-*$ & \\
\hline Complete & & \\
\hline
\end{tabular}

TABLE 3. Continued

\begin{tabular}{|c|c|c|}
\hline \multirow[b]{2}{*}{ Variable } & \multicolumn{2}{|c|}{$\begin{array}{c}\text { MR recurrence } \\
\text { (>2 grades) }\end{array}$} \\
\hline & SHR $(95 \%$ CI $)$ & $\begin{array}{c}P \\
\text { value }\end{array}$ \\
\hline \multicolumn{3}{|c|}{ Size of mitral annuloplasty, mm } \\
\hline $26-29$ & 1.00 & \\
\hline $30-31$ & $1.37(0.55-3.38)$ & .50 \\
\hline $32-34$ & $1.23(0.52-2.91)$ & .64 \\
\hline $36-48$ & $1.02(0.22-4.85)$ & .98 \\
\hline \multicolumn{3}{|l|}{ Type of mitral valve repair } \\
\hline Any posterior repair & $0.44(0.20-0.96)$ & .038 \\
\hline Isolated posterior repair & $0.56(0.27-1.16)$ & .12 \\
\hline Any anterior repair & $1.79(0.86-3.71)$ & .12 \\
\hline Isolated anterior repair & $2.26(1.05-4.89)$ & .038 \\
\hline Bileaflet intervention & $0.99(0.35-2.80)$ & .99 \\
\hline
\end{tabular}

group recently published a report of 1218 patients undergoing mitral valve repair for degenerative mitral valve disease with a follow-up of $11 \pm 4.5$ years. The 15 -year incidence of recurrence of moderate or severe MR was $13.3 \% .^{8}$ David and colleagues ${ }^{6}$ also recently reported a series of 840 patients with freedom from moderate-tosevere or severe MR of 96 and $90 \%$ at 10 years and 91 and $69 \%$ at 20 years.

We chose a rather stringent definition of progression of MR as an increase of more than 2 grades, and we also included death as a competing outcome. This definition could overestimate the incidence of clinically relevant recurrent MR. For instance, a patient progressing from no MR (ie, grade 0) to mild-to-moderate MR (ie, grade 2.5) is considered a failure. Therefore, we included a secondary potentially more meaningful clinical endpoint of postoperative MR progression to moderate-to-severe (grade 3.5 ) or severe (grade 4). When we used our more stringent definition of progression more than 2 grades with death as a competing outcome, the cumulative incidence of progressive MR at 5 and 10 years was $21.0 \%$ and $35.8 \%$. This number decreases to $7 \%$ and $26 \%$ at 5 and 10 years if one considers just those patients with moderate-tosevere or severe MR.

Predicting who will develop recurrent MR after mitral valve repair remains problematic. Mitral valve repair, unfortunately, does not cure the underlying disease, and disease progression often is implicated in those who fail. In our study, risk factors on multivariate analysis for progression of MR considering death as a competing risk were diabetes, previous coronary artery bypass grafting, and concurrent tricuspid valve repair. The presence of a posterior leaflet repair was protective from progression by 


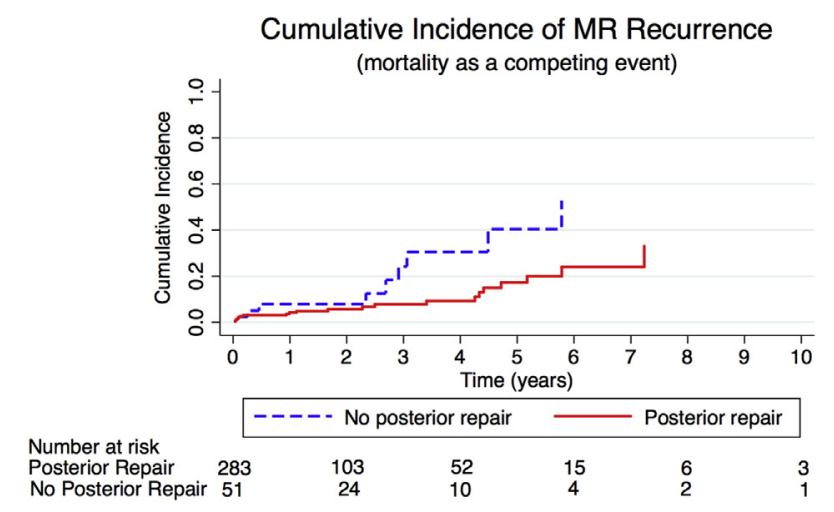

FIGURE 3. Nonparametric estimates of cumulative incidence of the probability of progression of mitral regurgitation more than 2 grades with death as a competing outcome for presence (dashed line) or absence (solid line) of any posterior leaflet repair. See Table E2 for confidence intervals.

univariate analysis $(P=.038)$ and of borderline clinical significant on multivariate analysis (SHR, 0.10; $P=.10$ ). Those with an isolated anterior leaflet repair were more likely to recur on univariate analysis (SHR, 2.26; $P=.038$ ).

Our results are similar to those of others who have found a multitude of factors associated with recurrent MR after mitral valve repair for primarily degenerative disease. Suri and colleagues ${ }^{8}$ found multiple predictive factors for recurrence, including age, mild intraoperative residual regurgitation, anterior leaflet prolapse, bileaflet prolapse, perfusion time, and lack of annuloplasty. David and colleagues ${ }^{6}$ found that age, isolated prolapse of the anterior leaflet, degree of myxomatous change, lack of mitral annuloplasty, and duration of cardiopulmonary bypass were associated with an increased risk of recurrence. Again, unlike our study, it is unclear which, if any, previous studies accounted for death as a competing risk in these analyses.

These data and our own support the concept that progression of MR after mitral valve repair is less with posterior leaflet pathology repairs and greater with anterior or bileaflet disease and/or repairs. To further analyze this, we looked at freedom from progression of MR in the subgroup of patients that had isolated posterior leaflet, segment 2 resections. Although not statistically protective from MR progression, freedom from recurrence at 5 years was greater than the overall group ( 83 vs $79 \%$ ). The other factors we identified, including diabetes, previous coronary artery bypass grafting, and concurrent tricuspid valve repair, are difficult to interpret and are likely related to selection of patients with more advanced disease.

Meticulous surgical technique is clearly a component to a durable repair. Our repair strategies have evolved but include several important principles. First, we prefer the simplest possible repairs, especially in elderly patients. Second, posterior repair typically includes a resection and annular plication of the posterior annulus, which decreases posterior leaflet height and increases tension on the remaining chordae. We also have decreased our use of neochordea in favor of more anterior resections, because these anecdotally seem more durable. Although others may advocate leaving anterior mitral valve pathology untreated, our preference is for repair. ${ }^{20}$ Last, we almost always place a true-sized posterior annular ring and were early adopters of this technique.

This analysis of outcomes after mitral valve repair is especially timely given the recent approval of the MitraClip (Abbott Vascular, Menlo Park, Calif) for severely symptomatic patients with severe MR who are not surgical candidates. $^{2,21}$ The MitraClip mimics the surgical edge-to-edge repair. The EVEREST (Endovascular Valve Edge-to-Edge REpair STudy) II trial randomized 279 patients with moderately severe or severe MR to percutaneous repair with the MitraClip or conventional repair. ${ }^{22}$ These patients were not considered high surgical risk and had a mean age of 67 years, which is very similar to our cohort of patients. At 4 years, percutaneous repair was associated with similar mortality and symptomatic improvement but a greater rate of MR requiring repeat surgery. ${ }^{21,22}$ The initial commercial experience with transcatheter mitral repair in the United States recently was reported in which 456

\section{Multivariate Analysis with mortality as competing risk for MR progression}

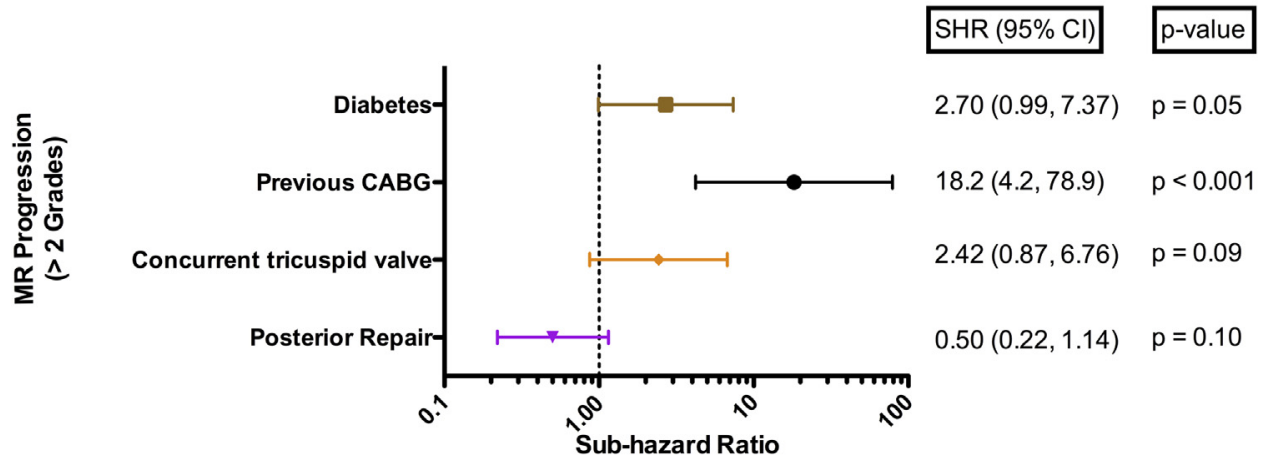

FIGURE 4. Forest plot of variables associated with MR progression more than 2 grades after multivariate adjustment. Solid point represents hazard ratio. Bars represent $95 \%$ CIs. $M R$, Mitral regurgitation; $C A B G$, coronary artery bypass grafting; SHR, subhazard ratio; $C I$, confidence interval. 
patients with a median age of 83 years underwent MitraClip placement. ${ }^{23}$ Median Society of Thoracic Surgery 30-Day Predicted Risk of Mortality scores were high (7.9\%$10.0 \%)$. Procedural success and reduction of MR was achieved in $91 \%$ of patients, suggesting that this treatment is effective in a commercial setting in selected patients at high risk for surgical intervention. ${ }^{23}$

The recommendations and approval currently limit this technology to patients of prohibitive operative risk. ${ }^{24,25}$ As the MitraClip evolves and other repair and replacement technologies enter clinical trials in an attempt to prove noninferiority (or superiority) to surgical techniques and applicability to lower risk patients, it is important that we consider the excellent outcomes with surgical mitral valve repair. Every surgeon will have to assess whether they truly have equipoise and whether it is ethical to enroll what would have otherwise been an appropriate surgical candidate for mitral valve repair in one of these trials, particularly those with posterior leaflet disease.

This study has numerous limitations. This was a retrospective cohort study from a single center and has the inherent limitations of this type of analysis. Although our attempts to obtain complete follow-up were exhaustive, we unfortunately did not obtain routine TTE at prespecified times, and follow-up studies were not available for $25 \%$ of patients. We largely relied on outside TTE reports, which made controlling for consistency and adjudication impossible. It is possible we have overestimated the longitudinal recurrence of MR as the probability of a patient having a follow-up TTE may have been greater for a clinical indication; however, we also cannot rule out that we have underestimated the longitudinal recurrence of MR because patients may have had recurrent MR and simply been treated medically.

Although a longitudinal mixed-model analysis to assess ordinal MR across time would have been preferable based on reporting guidelines, the lack of previous echocardiograms before recurrence in a large number of patients made this type of analysis impossible, necessitating dichotomizing outcomes and analyzing them with actuarial methods as if they were discrete events. We also did not include patients in whom repair was attempted and failed. We did not feel that our database was robust enough to impute data, because this would have likely introduced as many errors as it fixed. Regarding reoperations, we did not include patients in whom reoperative mitral surgery was indicated but the patient either refused or was deemed too high risk. Last, it is difficult to compare results between studies because of differing definitions, patient populations, comparator groups, and variation in TTE follow-up.

Assurance of complete and current survival is difficult to obtain in any retrospective study. We carried out an exhaustive and systematic effort to verify survival by contacting the referring physicians, the patient, or patient's next of kin followed by a search of obituaries at the patients last known address. If we still could not locate the patient, we relied on a search of a current version of the Social Security Death Index. We believe that our mortality data are complete and accurate, but the possibility of missed deaths remains a possibility.

Our study confirms the results of other centers of excellence. Mitral valve repair is associated with excellent survival, is durable with low rates of need for reoperation, and MR appears less likely to recur with posterior leaflet repair. We should be cognizant of these surgical results during this era of ever increasing application of percutaneous mitral valve therapy.

\section{Conflicts of Interest Statement}

Drs Bowdish and Cohen have received grant support from Medtronic, Inc, in the last 36 months for an unrelated project. Dr Cohen is on the Scientific Advisory Board and Speakers Bureau of Medtronic Inc. All other authors have nothing to disclose with regard to commercial support.

We thank Ramsey Elsayed, MD, assistance with data collection for revisions.

\section{References}

1. Chatterjee S, Rankin S, Gammie JS, Sheng S, O’Brien SM, Brennan JM, et al. Isolated mitral valve surgery risk in 77,836 patients from the Society of Thoracic Surgeons database. Ann Thorac Surg. 2013;96:1587-94; discussion 1594-5.

2. Nishimura RA, Otto CM, Bonow RO, Carabello BA, Erwin JP III, Guyton RA, et al. 2014 AHA/ACC guideline for the management of patients with valvular heart disease: a report of the American College of Cardiology/American Heart Association Task Force on Practice Guidelines. J Thorac Cardiovasc Surg. 2014; 148:e1-132.

3. Vassileva CM, McNeely C, Spertus J, Markwell S, Hazelrigg S. Hospital volume, mitral repair rates, and mortality in mitral valve surgery in the elderly: an analysis of US hospitals treating Medicare fee-for-service patients. J Thorac Cardiovasc Surg. 2015;149:762-8.e1.

4. Atluri P, Stetson RL, Hung G, Gaffey AC, Szeto WY, Acker MA, et al. Minimally invasive mitral valve surgery is associated with equivalent cost and shorter hospital stay when compared with traditional sternotomy. J Thorac Cardiovasc Surg. 2016;151:385-8

5. Suri RM, Dearani JA, Mihaljevic T, Chitwood WR, Murphy DA, Trento A, et al Mitral valve repair using robotic technology: safe, effective, and durable. $J$ Thorac Cardiovasc Surg. 2016;151:1450-4.

6. David TE, Armstrong S, McCrindle BW, Manlhiot C. Late outcomes of mitral valve repair for mitral regurgitation due to degenerative disease. Circulation. 2013;127:1485-92

7. DiBardino DJ, ElBardissi AW, McClure RS, Razo-Vasquez OA, Kelly NE, Cohn LH. Four decades of experience with mitral valve repair: analysis of differential indications, technical evolution, and long-term outcome. $J$ Thorac Cardiovasc Surg. 2010;139:76-83; discussion 83-4.

8. Suri RM, Clavel MA, Schaff HV, Michelena HI, Huebner RA, Nishimura RA, et al. Effect of recurrent mitral regurgitation following degenerative mitral valve repair: long-term analysis of competing outcomes. J Am Coll Cardiol. 2016;67: 488-98.

9. Castillo JG, Anyanwu AC, Fuster V, Adams DH. A near 100\% repair rate for mitral valve prolapse is achievable in a reference center: implications for future guidelines. J Thorac Cardiovasc Surg. 2012;144:308-12.

10. Murashita T, Okada Y, Fujiwara H, Kanemitsu H, Fukunaga N, Konishi Y, et al. Mechanism of and risk factors for reoperation after mitral valve repair for degenerative mitral regurgitation. Circ J. 2013;77:2050-5. 
11. Stevens LM, Basmadjian AJ, Bouchard D, El-Hamamsy I, Demers P, Carrier M, et al. Late echocardiographic and clinical outcomes after mitral valve repair for degenerative disease. J Card Surg. 2010;25:9-15.

12. Gillinov AM, Blackstone EH, Nowicki ER, Slisatkorn W, Al-Dossari G, Johnston DR, et al. Valve repair versus valve replacement for degenerative mitral valve disease. J Thorac Cardiovasc Surg. 2008;135:885-93. 893.e1-2.

13. Daneshmand MA, Milano CA, Rankin JS, Honeycutt EF, Swaminathan M, Shaw LK, et al. Mitral valve repair for degenerative disease: a 20-year experience. Ann Thorac Surg. 2009;88:1828-37.

14. Galloway AC, Schwartz CF, Ribakove GH, Crooke GA, Gogoladze G, Ursomanno P, et al. A decade of minimally invasive mitral repair: long-term outcomes. Ann Thorac Surg. 2009;88:1180-4.

15. Johnston DR, Gillinov AM, Blackstone EH, Griffin B, Stewart W, Sabik JF III, et al. Surgical repair of posterior mitral valve prolapse: implications for guidelines and percutaneous repair. Ann Thorac Surg. 2010;89:1385-94.

16. Braunberger E, Deloche A, Berrebi A, Abdallah F, Celestin JA, Meimoun P, et al. Very long-term results (more than 20 years) of valve repair with Carpentier's techniques in nonrheumatic mitral valve insufficiency. Circulation. 2001; 104(12 suppl 1):I8-11.

17. Akins CW, Miller DC, Turina MI, Kouchoukos NT, Blackstone EH, Grunkemeier GL, et al. Guidelines for reporting mortality and morbidity after cardiac valve interventions. J Thorac Cardiovasc Surg. 2008;135: 732-8.

18. Coviello V, Boggess M. Cumulative incidence estimation in the presence of competing risks. Stata J. 2004;4:103-12.
19. Fine JP, Gray RJ. A proportional hazards model for the subdistribution of a competing risk. J Am Stat Assoc. 1999;94:496-509.

20. Gillinov AM, Cosgrove DM III, Wahi S, Stewart WJ, Lytle BW, Smedira NG, et al. Is anterior leaflet repair always necessary in repair of bileaflet mitral valve prolapse? Ann Thorac Surg. 1999;68:820-4.

21. Feldman T, Foster E, Glower DD, Kar S, Rinaldi MJ, Fail PS, et al. Percutaneous repair or surgery for mitral regurgitation. N Engl J Med. 2011;364 $1395-406$.

22. Mauri L, Foster E, Glower DD, Apruzzese P, Massaro JM, Herrmann HC, et al. 4 year results of a randomized controlled trial of percutaneous repair versus surgery for mitral regurgitation. J Am Coll Cardiol. 2013;62:317-28.

23. Sorajja P, Mack M, Vemulapalli S, Holmes DR Jr, Stebbins A, Kar S, et al. Initial experience with commercial transcatheter mitral valve repair in the United States. J Am Coll Cardiol. 2016;67:1129-40.

24. Testa L, Latib A, Montone RA, Bedogni F. Transcatheter mitral valve regurgitation treatment: state of the art and a glimpse to the future. $J$ Thorac Cardiovasc Surg. 2016;152:319-27.

25. Downs E, Lim S, Ragosta M, Yount K, Yarboro L, Ghanta R, et al. The influence of a percutaneous mitral repair program on surgical mitral valve volume. J Thorac Cardiovasc Surg. 2015;150:1093-7.

Key Words: mitral valve repair, posterior leaflet repair, recurrent mitral regurgitation, mitral valve reoperation, degenerative valve disease

Readers who found these articles interesting may also like to read the following papers found in recent and future issues of our sister publications, Seminars in Thoracic and Cardiovascular Surgery and Operative Techniques in Thoracic and Cardiovascular Surgery!

\section{Acquired: Mitral Valve}

ORIGINAL SUBMISSION: Should Moderate-to-Severe Tricuspid Regurgitation be Repaired During Reoperative Left-Sided Valve Procedures? Igor Gosev. Semin Thoracic Surg 2016:38-45.

Editorial Commentary: To Fix or Not to Fix? That is the Question. Kenton J. Zehr. Semin Thoracic Surg 2016:46-47.

ORIGINAL SUBMISSION: Assessment of Mitral Valve Repair With Exercise Echocardiography: Artificial Chordae vs Leaflet Resection. Sigurdur Ragnarsson. Semin Thoracic Surg 2017: In press.

Editorial Commentary: The Dance of 2 Devils: Mitral Valve Repair and Functional Mitral Stenosis. Bobby Yanagawa. Semin Thoracic Surg 2017: In press.

ORIGINAL SUBMISSION: A Comparison of 2 Mitral Annuloplasty Rings for Severe Ischemic Mitral Regurgitation: Clinical and Echocardiographic Outcomes. Khalil Fattouch. Semin Thoracic Surg 2016:261-268.

Editorial Commentary: Ischemic Mitral Regurgitation: The Value of Flexibility in the Quest for a Perfect Repair. Ronen Beeri and Amit Korach. Semin Thoracic Surg 2016:269-270.

ORIGINAL SUBMISSION: Comparative Histopathological Analysis of Mitral Valves in Barlow Disease and Fibroelastic Deficiency. Jesper Hjortnaes. Semin Thoracic Surg 2016:757-767.

Editorial Commentary: Angel in the Architecture and the Devil in the Details: Comparative Ultrastructure of Degenerative Mitral Valve Disease. Tomasz A. Timek. Semin Thoracic Surg 2016:768-769.

CURRENT READINGS: Similar Survival After Repair vs Replacement for Ischemic Mitral Regurgitation. Hisato Takagi. Semin Thoracic Surg 2016:748-756. 


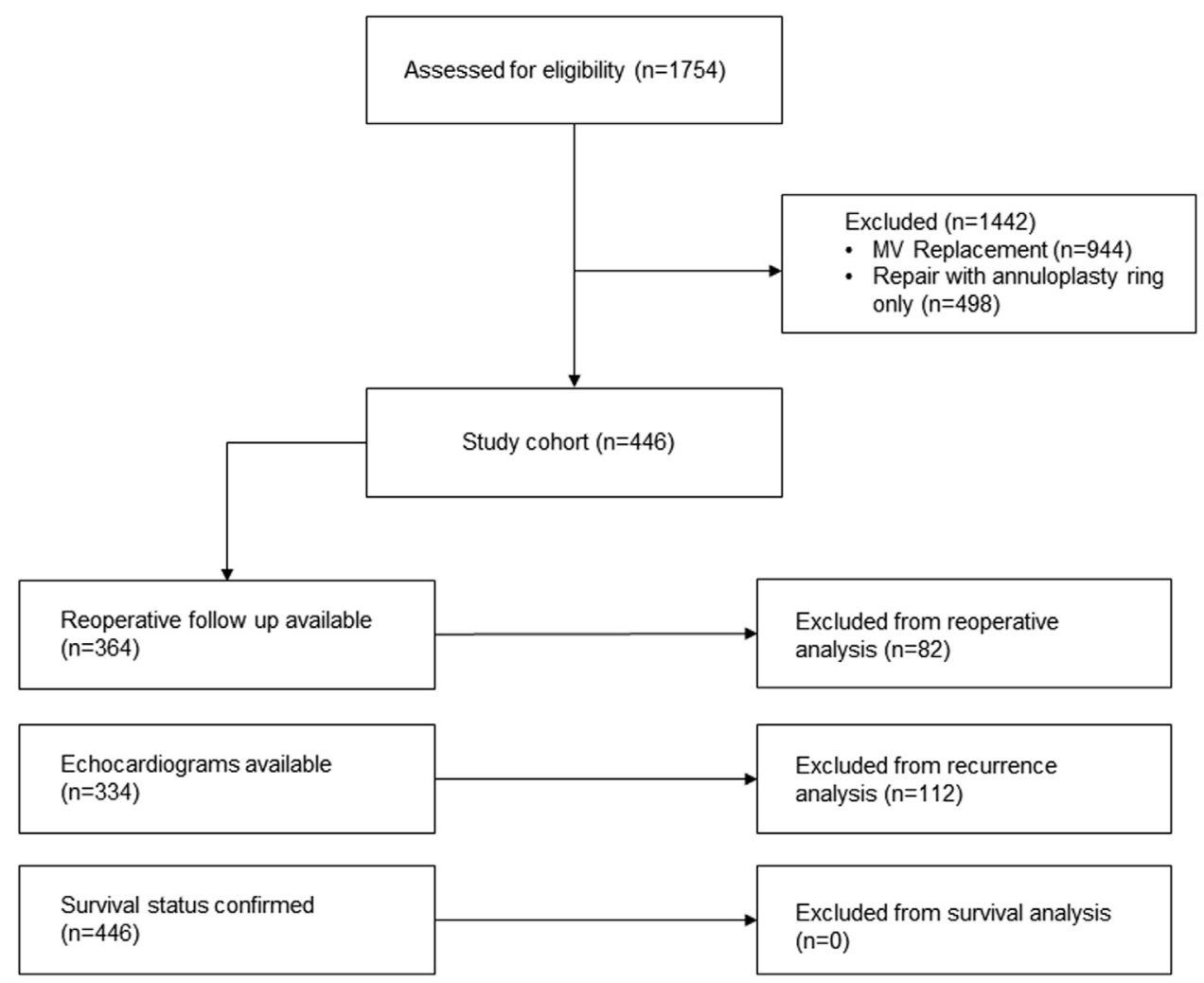

FIGURE E1. Consolidated Standards of Reporting Trials type flow diagram. $M V$, Mitral valve.

TABLE E1. Distribution of mitral valve replacement and repairs over time

Mitral valve procedures

\begin{tabular}{cccc} 
Replacement & Mitral valve procedures & \\
\hline 31 & All repairs & Repair: annuloplasty ring (only) & $\begin{array}{c}\text { Repair: leaflet repair with or } \\
\text { without annuloplasty ring }\end{array}$ \\
47 & 3 & 2 & 1 \\
53 & 13 & 7 & 6 \\
63 & 18 & 11 & 7 \\
50 & 25 & 13 & 12 \\
48 & 20 & 10 & 10 \\
45 & 54 & 26 & 28 \\
59 & 46 & 23 & 23 \\
47 & 55 & 22 & 33 \\
59 & 51 & 20 & 31 \\
63 & 49 & 10 & 30 \\
61 & 53 & 29 & 24 \\
65 & 93 & 41 & 52 \\
58 & 85 & 43 & 42 \\
60 & 70 & 27 & 43 \\
92 & 91 & 47 & 44 \\
43 & 62 & 21 & 41 \\
944 & 22 & 3 & 19 \\
& 810 & 364 & 446 \\
\hline
\end{tabular}


TABLE E2. CIs for time dependent figures

\begin{tabular}{|c|c|c|c|c|c|}
\hline & $\begin{array}{c}1 \mathbf{y} \\
(95 \% \mathrm{CI})\end{array}$ & $\begin{array}{c}3 \mathbf{y} \\
(95 \% \mathrm{CI})\end{array}$ & $\begin{array}{c}5 y \\
(95 \% \text { CI })\end{array}$ & $\begin{array}{c}10 \mathrm{y} \\
(95 \% \mathrm{CI})\end{array}$ & $\begin{array}{c}15 \mathrm{y} \\
(95 \% \mathrm{CI})\end{array}$ \\
\hline \multicolumn{6}{|l|}{ Figure 1} \\
\hline All patients & $96.9(94.6-98.2)$ & $95.7(93.1-97.3)$ & $94.8(91.8-96.7)$ & $94.0(90.4-96.2)$ & $94.0(90.4-96.2)$ \\
\hline \multicolumn{6}{|l|}{ Figure 2} \\
\hline Any posterior repair & $3.0(1.7-5.9)$ & $3.8(2.0-6.4)$ & $4.3(2.3-7.1)$ & $5.7(3.1-9.3)$ & $5.7(3.1-9.3)$ \\
\hline No posterior repair & $1.8(0.0-8.2)$ & $6.5(1.7-16.1)$ & $9.6(3.0-21.1)$ & $25.9(11.4-43.2)$ & $39.5(14.0-64.5)$ \\
\hline \multicolumn{6}{|l|}{ Figure 3} \\
\hline Any posterior repair & $4.2(2.1-7.4)$ & $7.8(4.2-12.9)$ & $17.2(9.5-26.9)$ & $33.0(15.0-52.3)$ & - \\
\hline No posterior repair & $7.9(2.0-19.2)$ & $24.2(8.9-43.5)$ & $40.4(16.5-63.4)$ & $52.8(21.8-76.6)$ & - \\
\hline
\end{tabular}

CI, Confidence interval.

TABLE E3. Baseline and operative characteristics of study patients with reoperative follow-up and without reoperative follow-up

\begin{tabular}{|c|c|c|c|}
\hline Characteristic & $\begin{array}{l}\text { Reoperative follow-up, } \\
\mathrm{n}=364\end{array}$ & $\begin{array}{l}\text { No reoperative follow-up, } \\
\qquad \mathbf{n}=82\end{array}$ & $P$ value \\
\hline Age, mean $\pm \mathrm{SD}(95 \% \mathrm{CI})$ & $60.38 \pm 13.5(58.9-61.8)$ & $61.8 \pm 59.2(59.2-64.4)$ & $.59^{*}$ \\
\hline Male, n (\%) & $239(65.7)$ & $57(69.5)$ & $.51 \dagger$ \\
\hline White, n $(\%)$ & $289(79.4)$ & $54(65.6)$ & $.009 \dagger$ \\
\hline BMI, mean $\pm(95 \% \mathrm{CI})$ & $26.0 \pm 5.4(25.4-26.6)$ & $26.2 \pm 4.2(25.3-27.2)$ & $.24 *$ \\
\hline Diabetes, n (\%) & $29(8.0)$ & $8(9.8)$ & $.60 \dagger$ \\
\hline Posterior repair, $\mathrm{n}(\%)$ & $306(84.0)$ & $71(86.6)$ & $.57 \dagger$ \\
\hline Anterior repair, $\mathrm{n}(\%)$ & $108(29.7)$ & $24(29.2)$ & $.94 \dagger$ \\
\hline Previous MV surgery, $\mathrm{n}(\%)$ & $6(1.7)$ & $1(1.2)$ & $.78 \dagger$ \\
\hline Concurrent procedure, $\mathrm{n}(\%)$ & $119(32.7)$ & $21(25.6)$ & $.212 \dagger$ \\
\hline Concurrent tricuspid valve procedure, $\mathrm{n}(\%)$ & $27(7.4)$ & $4(4.9)$ & $.41 \dagger$ \\
\hline Cardiopulmonary CCT $>90 \mathrm{~min}, \mathrm{n}(\%)$ & $135(38.0)$ & $37(46.3)$ & $.13^{*}$ \\
\hline Crossclamp $>60 \mathrm{~min}, \mathrm{n}(\%)$ & $136(37.9)$ & $41(51.6)$ & $.10^{*}$ \\
\hline Concurrent other valve surgery, $\mathrm{n}(\%)$ & $43(11.8)$ & $5(6.1)$ & $.13 \dagger$ \\
\hline Concurrent CABG, n (\%) & $17(4.7)$ & $4(4.9)$ & $.94 \dagger$ \\
\hline Previous cardiac surgery, n (\%) & $16(4.4)$ & $7(8.6)$ & $.17 \dagger$ \\
\hline
\end{tabular}

$\dagger$ Pearson $\chi^{2}$ test.

TABLE E4. Baseline and operative characteristics of study patients with and without MR progression follow-up (echocardiogram)

\begin{tabular}{|c|c|c|c|}
\hline Characteristic & $\begin{array}{l}\text { MR progression follow-up, } \\
\qquad \mathbf{n}=334\end{array}$ & $\begin{array}{l}\text { No MR progression follow-up, } \\
\qquad \mathrm{n}=112\end{array}$ & $P$ value \\
\hline Age, mean $\pm \mathrm{SD}(95 \% \mathrm{CI})$ & $60.6 \pm 13.2(59.1-61.9)$ & $60.9 \pm 13.2(58.4-63.3)$ & $.89 *$ \\
\hline Male, n (\%) & $219(65.6)$ & $77(68.8)$ & $.54 \dagger$ \\
\hline White, n (\%) & $266(79.6)$ & $77(68.8)$ & $.018 \dagger$ \\
\hline BMI, mean $\pm(95 \% \mathrm{CI})$ & $26.0 \pm 5.3(25.5-26.6)$ & $26.0 \pm 5.0(25.1-27.0)$ & $.76^{*}$ \\
\hline Diabetes, n (\%) & $27(8.1)$ & $10(8.9)$ & $.78 \dagger$ \\
\hline Posterior repair, $\mathrm{n}(\%)$ & $283(84.7)$ & $94(83.9)$ & $.84 \dagger$ \\
\hline Anterior repair, $\mathrm{n}(\%)$ & $99(29.6)$ & $33(29.4)$ & $.97 \dagger$ \\
\hline Previous MV surgery, n (\%) & $5(1.5)$ & $2(1.8)$ & $.83 \dagger$ \\
\hline Concurrent procedure, $\mathrm{n}(\%)$ & $109(32.6)$ & $31(27.8)$ & $.33 \dagger$ \\
\hline Concurrent tricuspid valve procedure, $\mathrm{n}(\%)$ & $23(6.9)$ & $8(7.1)$ & $.92 \dagger$ \\
\hline Cardiopulmonary CCT $>90 \mathrm{~min}, \mathrm{n}(\%)$ & $124(38.0)$ & $48(44.0)$ & $.24 *$ \\
\hline Crossclamp $>60 \mathrm{~min}, \mathrm{n}(\%)$ & $123(37.3)$ & $54(49.1)$ & $.24 *$ \\
\hline Concurrent other valve surgery, $\mathrm{n}(\%)$ & $38(11.4)$ & $10(8.9)$ & $.47 \dagger$ \\
\hline Concurrent CABG, n (\%) & $18(5.4)$ & $3(2.7)$ & $.24 \dagger$ \\
\hline Previous cardiac surgery, n (\%) & $13(3.4)$ & $10(8.9)$ & $.04 \dagger$ \\
\hline
\end{tabular}

$M R$, Mitral regurgitation; $S D$, standard deviation; $C I$, confidence interval; $B M I$, body mass index; $M V$, mitral valve; $C C T$, cross-clamp time; $C A B G$, coronary artery bypass grafting. *Mann-Whitney $U$ test. $†$ Pearson $\chi^{2}$ test. 